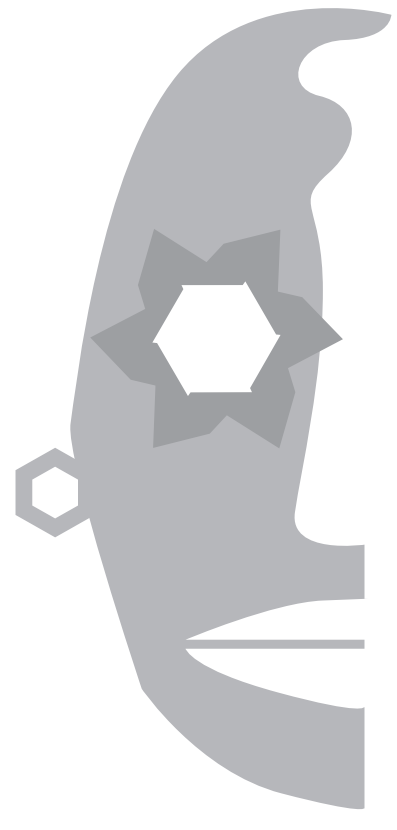

Maybell Vargas

Zúñiga

Universidad de Costa Rica

Costa Rica

\title{
Reynaldo de La Habana: un viaje a ninguna parte en la Cuba pos-revolucionaria
}

\section{RESUMEN}

El Rey de la Habana es la metáfora trágica del agotamiento de la Cuba castrista y el tortuoso parto de una nueva realidad social que no acaba de nacer. En las prietas páginas de una breve novela, repletas de violencia, bestialidad, sexo desaforado, heces y descarnada lucha por la vida, Pedro Juan Gutiérrez se erige como testigo de su época y el destino de su patria. Su telón de fondo es una Habana decadente, físicamente carcomida, donde el "sálvese cada uno como pueda" funciona como ley social. Esta obra coloca a su autor entre los novelistas latinoamericanos medulares en la bisagra entre el s. XX y el s. XXI.

Palabras clave: Cuba; literatura; Pedro Juan Gutiérrez; novela; realismo sucio, pícaro

\section{Abstract}

El Rey de La Havana is the tragic metaphor of the exhaustion of Castro's Cuba and the tortuous birth of a new social reality not yet been born. In the fast-paced pages of a short novel, full of violence, bestiality, boundless sex, faeces, and a fierce struggle for life, Pedro Juan Gutiérrez stands as a witness of his time, and the destiny of his country. Its backdrop is a decadent, physically rotten Havana, where "save yourself as you can" works as a social law. This endeavor places its author among the main Latin American novelists in the hinge between the twentieth century and the twenty-first century.

Keywords: Cuba; literature; Pedro Juan Gutiérrez; novel; dirty realism, rogue 


\title{
Introducción
}

\author{
"Solo un arte irritado, indecente, violento, grosero, \\ puede mostrarnos la otra cara del mundo, \\ la que nunca vemos o nunca queremos ver \\ para evitarle molestias a nuestra conciencia" (Gutiérrez, 1998, p. 105)
}

El Rey de la Habana de Pedro Juan Gutiérrez es la pequeña gran novela del Período Especial vivido en Cuba en los años 90.

La Unión Soviética colapsa en 1991. Con ella se desvanecen los subsidios masivos con que Cuba había podido defenderse del embargo norteamericano y los caprichos económicos de Fidel, perdiendo más del 80 \% del comercio exterior.

Anteriormente, Fidel había compensado tanto la expropiación generalizada de la propiedad como del derecho a la palabra con una multitud de programas sociales. La educación y la atención sanitaria cubanas eran de clase mundial. Varios indicadores sociales se volvieron superiores a los estadounidenses. La libreta daba acceso a muchos bienes. La igualdad de los sexos y las razas hicieron enormes progresos en Cuba. El trato estaba claro: entreguen la libertad a cambio de la seguridad y las necesidades vitales. Muchos cubanos lo aceptaron.

A inicios de los años 90, la miseria a niveles típicamente latinoamericanos reapareció en La Habana. Con ella la desigualdad, que ha seguido creciendo hasta hoy. En desesperación, Fidel declara el "Periodo Especial en tiempo de paz". Duraría hasta el año 2004, cuando creyó que los subsidios de Hugo Chávez permitirían regresar a su utopía.

Aspecto esencial del periodo especial fue la dolarización de la economía, con apertura al turismo y la inversión extranjera. Ello era necesario ante todo para mantener el nivel de vida de la casta privilegiada. Sin embargo, proporcionaba una leve válvula de escape a las masas, al legalizarse o tolerarse los pequeños negocios "familiares". A pesar de esto no se puede evitar el rápido desabastecimiento de los recursos básicos de alimentación para los cubanos, lo que lleva a este pueblo a una inmensa hambruna.

En efecto el turismo llegó y sigue llegando, atraído por la explosiva mezcla de las playas del Caribe, el sexo, la música, el ron. Y, no se olvide, el mito revolucionario, todavía tan potente como incongruente. Con base en este contexto, se examinan algunos de los puntos claves en la novela de Gutiérrez. 


\section{Centro Habana como espacio vivido}

El Rey de la Habana de Pedro Juan Gutiérrez está escrito en 1999, en medio de este periodo. Viene a ser su crónica en quintaesencia. Narra la corta vida de un mulato habanero quien, nacido exactamente el 7 de enero de 1981, llega a su precoz pubertad con la crisis.

Bolaño puede seguramente con razón al decir:

Más allá del sexo, de la droga y de la angustia por sobrevivir, el personaje central de las obras de Pedro Juan Gutiérrez es La Habana, una Habana miserable, comatosa, donde la palabra "revolución" ya ni es causa de risa. No, comatosas eran las viejas ciudades comunistas como Sofía o Bucarest, en la decadencia del sistema estalinista... La decadencia de La Habana es sin embargo similar a la de esas ciudades comunistas. (citado en Lalonde, 2012)

No obstante, la dictadura en Cuba y La Habana misma exhiben un sex appeal cuasi-romántico que nunca ejercieron otros satélites soviéticos. Es así, como la ciudad se convierte en otro personaje en el texto, entrecruzándose con los que transitan en ella, evidenciando el eco de las diversas voces configuradas allí y colocándose como medio de acción para las vivencias de Reynaldo.

Como ya se indicó, en 1989 los indicadores sociales de Cuba eran los mejores de Latinoamérica. Excepto en alojamiento. Nada de extrañar, porque este es un problema de producción, talón de Aquiles de cualquier sistema comunista. Las casas y palacios centenarios de La Habana, bajo la gran presión migratoria de comarcas más pobres, se habían convertido desde años atrás en atestadas colmenas de tugurios. Sigue muriendo gente cuando alguno de esos decrépitos edificios colapsa. Los supervivientes se mudan a los aledaños, semi-desmoronados a su vez, y el ciclo continúa. Asimismo, las deficiencias crónicas en transporte, servicios básicos de alimentación, agua y energía formatean la vida de Reynaldo, personaje arquetípico que dirige la mirada del lector por un viaje en una urbe laberíntica y en decadencia, donde su único destino no parece ser otro que la muerte trágica.

Al pensar en Centro Habana como un personaje que también cuenta su historia, no será casual que sea el epicentro que escoge el autor para situar la diégesis de su obra, donde los solares o "cuarterías" son los espacios característicos en esta zona. El hacinamiento, delincuencia y peligro constante de derrumbe, es el "pan nuestro de cada día" de sus habitantes. Este espacio en ruinas que, si bien podría representar un espíritu revolucionario ensombrecido y el desplome de la metrópoli, muestra a la vez un lugar efervescente de vida (una ciudad personificada agitada en la lucha humana por sobrevivir). De esta manera, Pedro Juan Gutiérrez no falla en su elección como afirma Whitfield (2010): 
El solar como un organismo viviente le permite a Pedro Juan ahondar con mayor profundidad en la vida animal que observa en las calles de Centro Habana y representar los aprietos de sus miembros individuales. Las calles están pobladas por formas de vida sobre las que coloca una clara lente zoológica. (p. 92)

Los protagonistas de Pedro Juan Gutiérrez serán los marginados sociales, los desprotegidos que deambulan por una ciudad desmaquillada, en abandono total. Todos ellos ubicados en el mismo campo de acción: Centro Habana, como otro personaje que ejemplifica la marginalidad y pobreza.

Esta será una ciudad que plasma una voz que cuenta los sucesos de una manera real, lo que según Portela (2003) otorga a la novela ese carácter de autenticidad:

\begin{abstract}
No es que cuente hechos reales a sangre fría (lo cual no aportaría ninguna garantía de auntenticidad: también se puede contarlos y ser un farsante, un fullero, un manipulador, en dependencia del recorte que se haga de la realidad, de la selección, o sea, de qué ponemos bajo el reflector y qué dejamos a la sombra); más bien se basa en hechos reales, es decir, los toma como punto de partida, los reorganiza y los modifica para tramar una historia sólida y concentrada, verosímil de principio a fin. (p. 67)
\end{abstract}

\title{
Un Rey en Centro Habana
}

Se debe notar que cuando escribe El Rey de la Habana (1999), Pedro Juan Gutiérrez posee ya un oficio, un estilo, una temática y un público, afinados en el anecdotario de la Trilogía Sucia de La Habana (1998), escrita un año atrás. Sin embargo, Rey, sin ruptura si se quiere, definitivamente es un animal diferente. Ahora el irónico Bocaccio caribeño de la Trilogía se reviste de un nihilismo shakesperiano.

La novela comienza con una escena de violencia atroz, de drama y miseria humana: "No habiendo conocido jamás a su padre, Reynaldo y su hermano son criados por una abuela enferma y una madre al borde de la locura" (Joachim, 2014, p. 173). No aparecerá ningún padre en el texto. La familia vive en un alojamiento miserable de una azotea. Reynaldo y su hermano se hallan en ella y en instantes, Nelson (su hermano) se convierte en homicida al matar a su madre sin proponérselo, para luego aventarse al vacío desde la azotea, lugar que se convierte en un espacio de sangre y muerte. Reynaldo, en posición de observador paralizado, es testigo de la muerte de su madre, su hermano y su abuela. Testigo mudo, que no aflojará en el empeño de olvidar, pero será de todas maneras arrastrado por este hecho inicial como una predestinación a la catástrofe. Este comienzo fija el tono del relato, que nunca flaquea, decae o se desvía, y a través de todas las peripecias sostiene al lector en el único objetivo del actor: seguir vivo, combatir el hambre. Lejos de restarle trazos, la uni-dimensionalidad hipnótica de Rey en su perenne guerra contra el hambre, lo constituye en un personaje inolvidable. 
El movimiento de la narración está guiado por Reynaldo, es el eje magnético que va a crear un campo espacial y temporal en el que ocurren los hechos. Es un viajero que no tiene un punto específico de permanencia. Sin asidero fijo, la vida de Rey oscila entre los diferentes espacios que le van apareciendo azarosamente en el camino y que dan forma al contenido del relato. Los únicos lugares que de alguna manera constituyen "su casa" son un contenedor y una choza construida por él mismo hacia el final de la novela, del otro lado de la bahía. El cuarto de Sandra, el mismo contenedor, la habitación de Magda y el Malecón, son sitios de paso a los que regresa ocasionalmente.

Reynaldo en su vaivén será un foco de atención para mujeres y homosexuales que de alguna manera se lo disputan como un trofeo. Por algo lo llaman el Rey, con su pene grande y abultado por dos perlanas de acero para ofrecer el máximo placer a sus diversas compañías sexuales. Es el macho alfa como el palomo que al inicio del texto utilizaban Rey y su hermano para cazar hembras de paloma:

hermoso palomo, macho y seductor, que volaba por encima de todos los edificios. Siempre aparecía alguna palomita incauta, admiradora de aquel bello galán. Y allá se iba. Alzaba el vuelo tras él y el palomo la conducía hasta su jaula para hacerle el amor a pierna suelta. (Gutiérrez, 1999, p. 11)

Si toda lectura es un viaje, muchas novelas son viajes de búsqueda también. En este caso, desde el comienzo hay en el aire barruntos de naufragio para el Rey; se adivina tratarse de un viaje a ninguna parte o más bien, nos advierte de su viaje a una muerte prematura.

\section{Una constatación}

Sin lugar a dudas, aunque con sus propias características, el autor se inscribe en la corriente del Realismo Sucio, a la que pueden considerarse pertenecientes autores como Charles Bukowski, el dominicano-norteamericano Junot Díaz o Zoé Valdés, también cubana de origen. Bolaño de hecho lo llama "el Bukowski de La Habana" (citado en Lalonde, 2012).

El "Realismo Sucio" es ante todo realismo. Escribe el polígrafo Slavoj Zizek:

La imagen de Cuba que se obtiene de alguien como Pedro Juan Gutiérrez... es reveladora: la realidad común de Cuba es la verdad de lo sublime revolucionario: la vida cotidiana de lucha por la supervivencia, desde la huida hasta las relaciones sexuales promiscuas violentas, de aprovechar el día sin ningún tipo de proyectos orientados al futuro. (2016, párr. 5)

También se ha vinculado El Rey de la Habana (1999) con la tradición española de la novela picaresca. Hay rasgos indudables, en la vivencia de Reynaldo y en 
el tono del relato en muchas de sus fases, del género picaresco. El hambre, la búsqueda incesante de dinero, el recurso a la delincuencia, el contraste con la sociedad "normal", el continuo vagabundaje, la aparente misoginia y la misma filosofía vital del Rey, parecen abonar la tesis de ver la novela de Pedro Juan Gutiérrez como una "cubanización" de la picaresca tradicional. Volveré sobre esta interpretación más adelante.

Entre las maravillas de la novela está la prodigiosa brevedad de sus frases. Abundan las de dos palabras, o incluso de una: "Se olió las axilas. Estaba cochambroso, con peste a sudor y a suciedad. Le gustaba ese olor. Le recordaba su casa. Pero no quería tener recuerdos de nada ni de nadie. Borró" (Gutiérrez, 1999, p. 32). Esto sucede poco después de escaparse del correccional donde estuvo luego de la desaparición de su familia. Cuando, vuelto a sus barrios, el olfato, el más primigenio y evocador de los sentidos, despierta sus recuerdos. Sin embargo, Rey se obliga al olvido. El narrador por su parte escatima en recursos lingüísticos, no así en la potencia de las palabras. Es una de las características del Realismo Sucio, donde la economía del lenguaje advierte una sobriedad en la narración. La carga semántica no solo se observa en sus breves frases o vocablos tácticamente escogidos, sino en la extensión misma del texto.

\section{Lo escatológico y sexual}

Las hazañas y peripecias sexuales de Rey constituyen paraísos del voyeur. El erotismo y el sexo están sistemática y profundamente mezclados con elementos de repulsión. En este sentido, el papel del olfato (omnipresente "olor a grajo") es uno de los aciertos de la novela. Reynaldo es un personaje con una sexualidad voluptuosa y siempre expuesta. Su placer se presenta en función de lo sucio: el olor alcalino del pene, el agrio de la vagina, la fetidez del ano, el tufo de los pies, la pestilencia de las axilas, actúan como poderosos afrodisíacos para Rey y su pareja favorita: "Rey se acomodó de frente, sacó su animal, que se endureció apenas olfateó el bollo apestoso y ácido de Magda, y allí mismo copularon frenéticamente, mordiéndose por el cuello" (Gutiérrez, 1999, p. 59).

Por el contrario, las parejas ocasionales del Rey que sufren la manía de la limpieza, le fuerzan a utilizar a fondo su imaginación de lo sucio para llegar al orgasmo:

Rey cerró los ojos y se descraneó con Magda. Cada vez que Daisy-o Rosa, quien sabe- intentaba subir a besarlo, él le mantenía la cabeza abajo. No quería oler la fragancia y limpieza de Daisy. Magda, suda, Magda, suda, con tu peste a grajo. Así mantuvo la erección más o menos y soltó mucho semen en la boca de Magda, o en la de Daisy, o en la de Rosa. (Gutiérrez, 1999, p. 177) 
Los grandes personajes crecen en el respeto de sus autores, como creció el Quijote en el de Cervantes. Precisamente el arte del narrador llega a su culmen cuando su creación habla por él. Hay momentos en El Rey de La Habana (1999) en que el narrador parece abandonarse, a su vez, al gozo del voyeur y se le escapan expresiones de placer. Particularmente reveladora es la soberbia escena orgiástica del baile de las mulatas al final del turno de la fábrica donde Rey trabajó y la masturbación masiva de los negros sobre ellas, en la que a la postre Rey participa. "Ya no pudieron resistir más. Era demasiado. Uno soltó su semen sobre la barriga y las tetas de aquella que lo pedía. Los otros no pudieron aguantar más y ahh, mucha leche" (Gutiérrez, 1999, p. 133).

\section{Lo sociológico}

Con todo, el narrador nunca pierde de vista el determinante socio-político esencial: que el Rey no tiene puesto en la nueva sociedad de violencia contenida que, a despecho de la casta gobernante, el periodo especial inevitablemente alumbra. Sociedad y violencia ejemplificadas por el personaje gordo con la cadena de oro que gobierna las carnicerías en la plaza del mercado. Al respecto, la violencia abierta en El Rey de la Habana (1999) es continua y con descripciones sangrientas: suicidios, homicidios feroces, trifulcas, huidas bajo disparos. Centro Habana durante la crisis se vuelve un lugar más peligroso. Sin embargo, cierto nivel de seguridad es parte del trato tácito entre el Estado y los cubanos; por lo tanto, cuesta creer que el alto grado de violencia manifiesto en la novela sea lo cotidiano. Dejando de lado la catastrófica escena original y el período del correccional, todo lo demás sucede en el transcurso de unos pocos meses. No obstante, el narrador no pierde el pulso: la violencia es consustancial a su historia y debe ser narrada como lo más normal del mundo. Un aire de veracidad desarma al lector.

\section{El amor imposible}

Otro tema álgido en el texto es la interacción entre Rey y Magda. Kafka es uno de los héroes de Pedro Juan Gutiérrez. Su frase sobre la imposibilidad de escribir y la imposibilidad de no escribir, ha dado fundamento a mil meditaciones sobre la angustia moderna. Muchos han debido de señalar que Pedro Juan Gutiérrez enfrenta un problema paralelo en su novela. En un ambiente de continua interacción con el otro sexo, el surgimiento del amor es un riesgo siempre presente.

"Una voz dulce de mujer le interrumpió" (Gutiérrez, 1999, p. 52). Semejante palabra, que no se prodiga en El Rey de la Habana (1999), significa el acorde que precede la irrupción de la heroína en la ópera. Magda y Reynaldo se ven obligados a separarse una y otra vez, en parte por las "misteriosas" desapariciones de ella, en parte por los continuos roces con la ley de él. Casi tanto como el hambre, la necesidad de Rey de volver a ver a la mujer de su vida es uno de los 
vectores dinámicos de la novela. El narrador nos aproxima al tema cuidadosamente: "Magda y él cada día templaban mejor. Con más cariño, tal vez, o más amor... A veces se trataban despectivamente, pero cada uno sabía que solo era de dientes para fuera" (Gutiérrez, 1999, p. 81).

El vaivén entre los tonos melosos y los agresivos es constante entre Rey y Magda. No faltan tampoco los clásicos pleitos:

Magda, vamos a hablar. — No vamos a hablar ni cojones, piérdete de mi vista. — Por lo menos dime... - Esto se acabó, Rey. Tu eres un barco. Yo necesito un hombre. ¡Un hombre!... Pero yo puedo... - Tú no puedes ni cojones. ¡Tú eres un chiquillo y un comemierda! Adiós. (Gutiérrez, 1999, p. 172)

La reconciliación no menos clásica viene con una emergencia causada por un escape de amoniaco, en que el pensamiento y la búsqueda de uno vuelan al otro. De modo que el narrador comenta: "Si aquello no era amor, se parecía mucho" (Gutiérrez, 1999, p. 195).

El derrumbe posterior de su edificio es la metáfora perfecta de que los días de su relación, sus propios días en este mundo, están contados.

¿Hay amor? Rey es un asesino que encuentra placer en el espectáculo horripilante de su hembra acuchillada (por añadidura un necrófilo, penetrando en ella dos veces y eyaculando dentro del cadáver). Pero Rey desde siempre es un desalmado, no pudo llegar a ser otra cosa. Roba a los pobres. Sin pensar un segundo sacrifica a Sandra y a quienquiera que sea para salvarse. Se ha distinguido en la autoagresión. En estado de ira es capaz de cualquier crimen.

¿Hay amor? La respuesta a esto toca a la idea misma de qué es ser humano y nos lleva a la imposibilidad de amar y a la imposibilidad de no amar, en un ambiente que no brinda condiciones para que surja una relación estable.

En una novela localizada en el inframundo de La Habana durante lo peor de la crisis, centrada en la supervivencia, Pedro Juan Gutiérrez logra recontarnos cuán difícil es amar y también cuán inconcebible vivir sin amor. Es uno de sus triunfos. Amar es imposible. No amar es imposible también. La misma supervivencia fracasa.

\section{La muerte}

Al final del texto, el narrador nos cuenta el largo tiempo de agonía que sufre Rey hasta su muerte, como una candela cuya flama se extingue lentamente hasta disiparse: "Tuvo una muerte terrible. Su agonía duró seis días con sus noches. Hasta que perdió el conocimiento. Al fin murió" (Gutiérrez, 1999, p. 218). 
La última línea del libro dice: "Y nadie supo nada jamás" (Gutiérrez, 1999, p. 218). Es tan esperada como obviamente falsa: pues lo sabemos todo, hasta el apetito y disfrute de los zopilotes con el cadáver de Reynaldo: "El cadáver se corrompió en pocas horas. Llegaron las auras tiñosas. Y lo devoraron poco a poco. El festín duró cuatro días. Lo devoraron lentamente" (Gutiérrez, 1999, p. 218).

El narrador omnisciente nos lo ha contado todo y relata su muerte lentamente como si no quisiera apartar la vista del Rey hasta que el último pedazo de carne sea devorado.

Como el mismo Joachim (2014) reconoce, esta muerte no recordada es incompatible con el carácter de autobiografia ficticia de toda obra picaresca. De modo que si bien la tesis del carácter picaresco de El Rey de La Habana (1999) capta aspectos importantes de la novela, parece insuficiente como interpretación.

Es el narrador omnisciente quien sobrevive para nosotros, para que la tragedia colectiva cubana que el Rey encarna no sea ignorada. A través de un personaje marginal, Pedro Juan Gutiérrez nos ha revelado la situación de desesperanza de la gran mayor parte del pueblo cubano durante el "período especial".

\section{Referencias bibliográficas}

Birkenmaier, A. (2001). Más allá del realismo sucio: El Rey de la Habana de Pedro Juan Gutiérrez. Cuban Studies, 32, 37-55.

Birkenmaier, A. (2004). El realismo sucio en América Latina: Reflexiones a partir de Pedro Juan Gutiérrez. Miradas: Revista del audiovisual, 6. Recuperado de http://www.eictv.co.cu/miradas/index.php?option=com content\&task $=$ view $\& \mathrm{id}=34 \&$ Itemid $=56$

Díaz Infante, D. (2014). Ruina, aura, melancolía. En Duanel Díaz Infante, La Revolución congelada. Dialécticas del castrismo (224-239). Madrid: Editorial Verbum.

Díaz Infante, D. (2014). La memoria inconsolable. En Duanel Díaz Infante, Días de fuego, años de humo. Ensayos sobre la Revolución cubana (37-44). Leiden: Almenara.

Díaz Infante, D. (2014). Flâneur, Prometeo, ruinas. En Duanel Díaz Infante, Días de fuego, años de humo. Ensayos sobre la Revolución cubana (143-152). Leiden: Almenara.

Gutiérrez, P. J. (1998). Trilogía sucia de la Habana. Barcelona: Anagrama.

Gutiérrez, P. J. (1999). El Rey de la Habana. Barcelona: Anagrama. 
Herrera Fuentes, A. (2013). Sexualidad, sociedad y civilización: en El Rey de la Habana (1999), de Pedro Juan Gutiérrez y La dama sonámbula (2007), de Joaquín Hurtado. En Rafael Modesto Gasperín Gasperín y José Carlos Vásquez Parra, Narraciones éticas. Desde la modernidad y la posmodernidad. México: Plaza y Valdés Ediciones.

Joachim, J.-L. (2014). El Rey de la Habana de Pedro Juan Gutiérrez: Variations cubaines autor du théme du pícaro. En Cecile Bertin-Elisabeth (Coord.), Les récits de la marginalité en Amérique (173-188). Centre de recherches interdisciplinaires en lettres, langues, arts et sciences humaines, Martinique: Caraïbéditions.

Lalonde, B. (20 de agosto de 2012). Roberto Bolañonous parle de Pedro Juan Gutiérrez. Recuperado de https://www.youtube.com/watch?v=Op6AVdXD9do

Ludmer, J. (2004). Ficciones cubanas de los últimos años: el problema de la literatura política (357-371). En Anke Birkenmaier y Roberto González Echeverría (Eds.). Cuba. Un siglo de literatura (1902-2002). Madrid: Editorial Colibrí.

Portela, E. L. (2003). Con hambre y sin dinero. Crítica: Revista cultural de la Universidad Autónoma de Puebla 98, 61-80.

Suchlicki, J. (2006). Breve historia de Cuba. Los Angeles, CA: Pureplay Press.

Witfield, E. (2010). Mercados en los márgenes: El atractivo de Centro Habana. Revista Katatay, VI (8), 86-106.

Zizek, S. (30 de noviembre, 2016). El tardío fin del siglo XX. El mundo. Recuperado de http://www.elmundo.es/opinion/2016/11/30/583dcd3422601df40f8b4596.html 